\title{
Transgendering women's space: A feminist analysis of perspectives from Australian women's services
}

\author{
Lorene Hannelore Gottschalk
}

School of Business, University of Ballarat, PO Box 663, Ballarat, Vic. 3353, Australia

Basic human rights such as the right to work and to access services on the basis of characteristics such as race or sex and various other categories including gender identity are enshrined in legislation in many countries. Yet there are times such as those written about by Mathen (2004) when the rights of one minority group appear to clash with those of another. The rights of women born and raised female and those of male to female transgenders (MTFs) is one example of conflicting rights. This article discusses whether self identification as a woman, by a man raised male, should give right of access to women's groups and services such as women's refuges and women's health centres. One of the aims of transgender activist and support groups, for example Press for Change in the UK, Australian WOMAN Network and The Gender Centre in Australia, is to enable MTFs to access such women's spaces, both as clients and as workers (McDonald, 2006). The Gender Centre states in its Transgender Discrimination Fact Sheet that,

"For example, in general, if you are a male to female recognised transgender person you have the legal right to be considered for a job that is legally allowed to be for women only. Similarly, in general, you have the legal right to receive a service targeted at women only" (The Gender Centre Inc., 2005).

Women's spaces were set up to service the interests of women as a subordinate group and to service the special needs of women in various areas such as health and in particular to provide refuge and assistance for women escaping from male violence (Kaplan, 1996; Murray, 2002). They came about when feminists in the 1970s became aware of the extent of men's violence in the family and the need for 
their partners and children to find safe refuge (Sweeney, 2004). Feminists also became aware of the extent and seriousness of sexual assault, hence the establishment of Centres Against Sexual Assault (CASA). Such women's spaces provide services to women and also mutual support and a forum for women's concerns and consciousness-raising.

Transgender people argue that they have similar needs (Feinberg, 1996). On the one hand they, like women, have unique health issues albeit caused by hormone treatment and sex realignment surgery. Furthermore they are reported to experience discrimination, harassment and violence from men, as do women (Pitts, Smith, Mitchell, \& Patel, 2006) and so also have a need for safe refuge.

The question arises whether MTFs should expect women's organisations to meet their unique MTF needs, furthermore whether women who are born and raised female should have the right to gather to the exclusion of those born male and raised male and whether women's groups such as self-help groups and refuges should be allowed to exclude MTFs.

The determination of MTFs to enter women's spaces as workers, clients and members, has led to considerable stress within women's communities (Price, 2007; Stuart, 2006). Some welcome MTFs on equity grounds (McDonald, 2006) while others within women's communities strongly oppose the inclusion of MTFs insisting that they are not 'real' women and thus cannot empathise with the experiences of women born and raised female (Greer, 1999; Jeffreys, 2008; Raymond, 1994; Sweeney, 2004). In some cases activism by transgender lobby groups has led to the closure or erasure of women's groups and the suspension of festivals (McDonald, 2006; Sweeney, 2004; Wales, 1999).

There is some work that has looked at the implications for women of MTFs seeking to enter lesbian groups or women's festivals such as the Michigan Womyn's Music Festival. There seems to be no research that has examined the implications for women and for organisations providing a service to women when MTF transgender people seek to enter spaces, either as clients or as workers, that have been reserved for women in order to meet women's special needs. This article reports on an exploratory study that sought to examine the extent to which management staff in women's organisations and women's support groups:

- are aware of implications of transgender inclusion both as workers and clients;

- have developed policies about transgender inclusion; and

- have experienced transgender inclusion or attempts at inclusion and how they have dealt with this.

This article reports on women's health centres, Centres Against Sexual Assault and women's refuges.

\section{Women-only space and the transgender challenge}

The emphasis of past research about transgenderism has been in the areas of aetiology and more recently in areas such as transgender identity formation (Devor, 2004) and disclosure of transgender status and reactions to disclosure from family and others (Pearlman, 2006). The major writing about transgenders, both research based and in the popular media, discusses transgenderism from the perspective of transgendered people. Web sites, articles and books discuss their experience of gender dysphoria and the diagnosis of Gender Identity Disorder which is required for them to be recognised as a transgender (Gurney, 2006; Hausman, 2003; Meyer, 1982; NHS Direct, 2008; Rottnek, 1999). There are many works that describe their transitioning experiences (Burns, 2005; Cowell, 1954; Feinberg 1996; Morris, 1975; May, 2005; Rees, 1996).

There is little research that examines the social and political implications of transgenderism, Janice Raymond (1994) being a notable exception. Concern about the increasing diagnosis of transgendered people, and the medical industry that developed around transgenderism was first written about by Janice Raymond in 1979 and reprinted in 1994. She alerted readers to MTFs in women's sport, in women's organisations, for example an all women recording company, and other women's spaces. Raymond argues against trans-inclusion and notes that, "because transsexuals have lost their physical 'member' does not mean they have lost their ability to penetrate women - women's mind, women's space, women's sexuality" (Raymond, 1994, p.104).

Jeffreys (2008) shows particular concern about the implications of legislation such as the UK Gender Recognition Act of 2004, which enables men who have changed their gender, whether or not they retained their penis or are receiving hormone treatment, to legal recognition as a woman. Such men are able to legally avail themselves of any space or service previously reserved for women only. As Jeffreys (2008) points out, if such men choose not to undergo hormone treatment or surgery they are indistinguishable from any other man and their presence in women's space negates the purpose for which the spaces were established in the first place.

Women's spaces providing social support and other services were first set up in Australia in the late 19th and early 20th centuries during the first wave feminist movement (Blair, 1984; Freedman, 1979; Kaplan, 1996). In the 1970s, the government agreed to provide financial assistance to establish and run women's refuges and by the end of that decade there were over 100 funded refuges across Australia (Johnson, 1981; Kaplan, 1996; Murray, 2002). Women's health centres are also government funded.

Women-only services such as refuges, CASAs and health centres fulfilled a desperate need. The extent of sexual assault and domestic violence was only brought to light by feminist movements, both first and second wave feminism (Kaplan, 1996; Lake, 1999). The benefits of providing services to meet women's special needs are well documented. According to Kaplan (1996) the considerable success of the health-care movement is attested to by the focus on women's medical issues previously neglected in medical research and a decline in disease and maternal and neo-natal death rates.

The impact on women of male violence and sexual assault is also well documented by feminist authors (Johnson, 1981; Herman, 1992). Herman (1992) clearly names sexual and domestic violence as trauma for the victim and equates such trauma with war combat and political terror. She demonstrates vividly how such traumatic events are similar and result in post traumatic stress disorder for the victims. Behaviour described by Herman such as imprisonment in the home and stalking and violence if the woman attempts to flee, demonstrates the significant need to have refuges for women and children. In discussing refuge and the recovery 
process from violence Herman (1992) points to physical and emotional safety as the first and major need of the survivors. Most crucial is separation from the source of violence, the perpetrator.

Historically when services were mainstreamed, women's special needs were usually 'invisible' and frequently neglected (Freedman, 1979; Kaplan, 1996). According to Freedman (1979) this occurred after the first wave feminist movements when women's spaces were mainstreamed and is evidenced by the fact that the incidence of domestic violence and sexual assault which was well known in the early 20th century had to be 're-discovered' by second wave feminists. Creating women-only space such as women's refuges and women's health centres as well as bookshops, women's festivals etc., according to Riger (1994), has been one of the outstanding achievements of the second wave feminist movement.

Such women's spaces have faced many challenges over the years (Riger, 1994), however one of the greatest challenges is the challenge by other groups including men and MTFs (Mathen, 2004). The rights of MTFs as a minority group came into conflict with the rights of women as a minority group when moves towards 'transliberation' occurred (Feinberg, 1996; Kaplan, 1996). In the USA transgender activists started to lobby for inclusion in women's spaces such as the National Organisation of Women (NOW) and the Michigan Womyn's Music Festival as well as lobby for inclusion in antidiscrimination legislation. In 1994 one chapter of NOW drew up a resolution in support of transgendered people (Feinberg, 1996).

Feinberg (1996) supports the right of MTFs to enter women's space and the safety such space provides. Feinberg's idealised vision is that everyone who identifies as a woman deserves and should get the support of women. Furthermore Feinberg suggested that "female-to-male transsexual brothers" should also be welcome in women's events and at lesbian bars (1996, p.117).

The endeavour of MTF activists to gain access to women's space for MTFs has led to the 'Great Trans Debate' (eminism. org, 2006). The debate questions whether men born and raised male can be women and, in many cases, lesbians or whether an MTF is, and always has been, a man. Radical feminists support the rights of transgenders to live without discrimination but do not accept that they are women (Greer, 1999; Jeffreys, 1997, 2008; Kline, unpublished; Raymond, 1994; Sweeney, 2004). On the Great Trans Debate website of Summer 2005 (eminism.org, 2006) a contributor commented that the MTF push to occupy women's safe spaces - from lesbian spaces to rape crisis centres, should be seen as cultural and political appropriation. Germaine Greer accuses MTFs of a lack of insight about the extent of their acceptance as women, noting that when "he forces his way into the few private spaces women may enjoy and shouts down their objections and bombards the women who will not accept him with threats and hate mail, he does as rapists have always done" (Greer, 1999, p.74). Sweeney (2004) agrees with Greer that the MTF challenge to enter women's spaces demonstrates their inability to empathise with women, while at the same time having the power to define socially and in the law what a woman actually is. Greer (1999) also points out that women were never asked whether they recognised MTFs as women but rather they have been obliged to accept MTFs as women because they self identify as women. This self identification in their view gives them the right to access any space reserved for women.

One of the first 'spaces' that MTFs lobbied to attend was the Michigan Womyn's Music Festival (Morris, 2005). Much has been written about the festival. Ruby (2003) commented on the feelings of freedom she experienced in the festival grounds, free from the fear of "street harassment" and free from men's tendency to "take over conversations" (Ruby, 2003, p.14). Transgender activism put an end to the freedom spoken of by Ruby. Mantilla (2000) writes in Off Our Backs of an 'invasion' of Michigan Womyn's Festival in the mid 1990s by MTFs who used tactics such as setting up a Camp Trans protest group outside the festival boundary. They made their presence felt by broadcasting loud male vocals into the women's festival quiet area in the evenings (Morris, 2005) and engaged in protests such as a pre-operative MTF entering the women's showers naked (Mantilla, 2000; Morris, 2005). This is an example of the sort of aggressive strategies discussed by Greer (1999).

Recently MTFs have been using the courts in seeking to enforce what they perceive as their right to access women's spaces. Vancouver Lesbian Connection (VLC) and Vancouver Rape Relief and Women's Shelter (VRRWS) are other examples of occasions when the rights of one group, MTF, are in conflict with the rights of another group, women born and raised female (Mathen, 2004). VLC had initially accepted MTF, Mamela, as a member but later revoked Mamela's membership on the grounds of aggressive and sexually offensive behaviour. Mamela took legal action but VLC did not have the energy or the resources to fight the case and disbanded (Wales, 1999). VRRWS refused training to MTF, Nixon, who sought to become a counsellor at the Centre, on the grounds that women are oppressed by men from birth and Nixon was recognised as a man on the basis of appearance (Mathen, 2004). VRRWS's position was that women must feel safe with the persons providing service to them and that such safety was compromised if a woman, who was a victim of male violence, is offered a service by a man, or a person who had not always been a woman and was raised as a male (Mayeda, 2005). After a 10 year battle VRRWS won on appeal.

As is noted by Mathen (2004, p.308) VRRWS resistance to accepting a post-operative MTF, "is partly attributable to the fear of opening a Pandora's Box that will complicate attempts to exclude other, more challenging categories of persons, up to and including men." Indeed even men, who identify as men, have argued that their qualifications should be considered adequate to work in organisations providing support services to women. For example again in Canada, at the Human Rights Tribunal, a man won the right to work in a women's shelter but this decision was overturned on appeal by using the VRRWS decision as a precedent (VRRWS, 2006).

Women's health centres are also under challenge by MTF activists who expect the centres to cater to their special needs. Health care given by and for women has a long history and according to Webb (1986) has long been resisted by the male medical fraternity to varying degrees, including laws passed by parliament to prevent women from practising medicine. The establishment of women's health centres staffed by women is a part of women's struggle to gain control over their 
own health (Kaplan, 1996). MTF activism has achieved some success in the endeavour to have women's health centres cater to their needs. Many accept MTF clients. The women's health service funded by famous lesbian activists Del Martin and Phyllis Lyon and established to provide health care and health education for women, especially for lesbians, has changed its name from Lyon Martin Women's Health Services to Lyon Martin Health Services as it now also provides health care for transgender people (Lyon Martin Health Services, 2008).

Transgender support groups seek to educate organisations including women's groups to accept MTFs. The Gender Centre in Australia, which has proactively approached women's services, state they are "committed to educating the public and providers" and that they provide support and training to organisations and service providers (The Gender Centre Inc., 2006). The Canadian group, Trans Alliance Society, have undertaken a study (Darke and Cope, 2002) on transinclusion which has resulted in a publication written to inform women's services such as refuges and sexual assault centres about trans-inclusion. This publication by Darke and Cope is analysed by Sweeney (2004) who concludes that while she supports the rights of MTFs to be free from discrimination these rights should not transcend the rights of women born and raised female and sees the solution in the formation of "separate autonomous spaces for trans-women by trans-women themselves" (Sweeney, 2004, p.84).

Feminists such as Raymond and Jeffreys proclaim the benefit of women-only space and argue that MTF inclusion is detrimental to women seeking the services they provide. Freedman (1979) concludes that women's spaces are essential to women on many levels and argued that historically, with assimilation into male dominated institutions, they lost momentum and lost the networks that made the gains for women by feminists possible.

"The decline of feminism in the 1920s can be attributed in part to the devaluation of women's culture in general and of separate female institutions in particular" (1979, p.524).

Freedman (1979, p.525) expressed concern that something similar could happen after the second wave feminist movement and argues "Our common identities and heritage as women can provide enormous personal and political strength as long as we claim the power to define what women can be and what female institutions can achieve".

\section{Methodology}

Research methodology should reflect the ontological assumptions and theoretical perspective of the researcher. My ontological assumption is social constructionism. Consistent with this I have chosen feminist critical inquiry as my theoretical perspective and approach to this research (Collis \& Hussy, 2003; Crotty, 1998).

This qualitative exploratory study draws predominantly on the findings of in-depth, one on one interviews, as well as email submissions. Overall nineteen women participated in this study.
Fifteen women who were principals, managers or coordinators of women's spaces participated in in-depth one on one interviews. The organisations were:

- Centres Against Sexual Assault (CASAs) (7)

- domestic violence refuges (4)

- women's health centres (4).

They held various titles but for ease of writing all interviewees who were in charge of centres will be referred to in this article, as managers.

Email communication was conducted with another four participants who had been associated with the organisations. One of these had been a worker in one of the Women's Health Centres that accepted MTF transgenders. One had worked in a refuge. Two had worked as consultants. One of the consultants, after the email exchange, also participated in a telephone interview.

The study was conducted in Australia. The majority of interviewees were from Victorian organisations from Melbourne and two regional cities, one from Canberra, four from Sydney three from Brisbane and one from Adelaide. They were recruited by the researcher telephoning the Centre, explaining the nature of the research project, and requesting an interview. Three of the email interviewees were recruited through a feminist email network. Another email contact occurred through snowballing. Discussion with participants in New South Wales, South Australia, Tasmania and Queensland were telephone interviews and with the Victorian participants face to face interviews were held. For purposes of anonymity and confidentiality I am unable to be more specific about the nature of the organisations in each State, as there were only a small number of interviewees.

The main themes explored in the interviews were:

- the idea of women-only space;

- awareness of transgender inclusion;

- employment policies about inclusion of men and MTFs; and

- experiences of inclusion of MTF transgenders as either workers or clients.

The interviews were audio-taped and transcribed. The data were organised and checked with the interviewees when clarification was necessary. A thematic analysis of the interviews was conducted according to the pre-existing themes that formed the core interview questions, plus unanticipated emerging themes.

Ethics approval for this research was obtained from the University of Ballarat Ethics Committee. Codes are used in the discussion of findings when respondents are quoted. The organisations are coded as follows:

- WH - women's health centres

- CASA - Centre Against Sexual Assault

- WR - women's refuge.

The term transgender in this research is used to describe those who seek recognition as the opposite sex on a long term or permanent basis. Other terms used in the popular and academic literature include transsexual, trans-women and trans-men. The terms above are not used to cover related phenomena such as transvestism, or 'drag' by men which is temporary and occasional, and transvestism and drag are not explored in this study. Transgenders can be either male to 
female (MTF) or female to male transgenders (FTM). The focus of this study is on male to female transgenders.

\section{Findings and discussion}

The decisions made by the centres involved in this study about whether or not they allowed MTFs to be workers or clients were based upon whether or not they believed MTFs to be women. Most of the centres are women's spaces, staffed by women and providing a service for women.

In the following discussions the interviewees' opinions about a safe space for women are explored, and how their beliefs about men and MTF transgenders as employees and clients, aligned with their philosophy.

\section{Women-only space}

The mission, or reason for being, of the majority of the organisations represented in this study is to provide a service for women, by women. Some also provide services for men. A minority was prepared to employ men, but only one did at the time of the interview. The interviewees were unanimous in their opinion that their service provided a safe space for clients. In the case of CASAs and domestic violence refuges the concern was safety from perpetrators, overwhelmingly men. In the case of women's health centres it was a safe space for women to discuss sensitive health issues with female health professionals who were especially trained to deal with women's health and well-being needs. Thus the organisations tended to be staffed by women with men often specifically and sometimes legally excluded. The following comments from interviewees support the emphasis they placed on a service provided for women, where they could have their needs met, and share experiences in a safe environment free from male domination.

CASA5: "Our clients are women only, run out of a 'women's house' so it is a strictly women's only space. Even with trades people all efforts made to find female tradies. All staff are women - we have exemption under EEO."

WH1: "One of the things I am most aware of personally is the potential for somebody who has experienced violence or who is experiencing violence....and they walk over the threshold here they do feel safe...so you would not want to jeopardise that. So we have a long tradition of being women focused and over those years we've developed an expertise around women, physical, emotional and social health issues and because we're a women only staff as well there's a lot of interaction and safety. It is a cooperative female environment in which to work, safe from men."

Women's space is also seen to provide a consciousnessraising forum for women, allowing women to share stories, experiences of violence and to learn about the institutionalisation of male dominance as articulated by CASA5.

CASA5: "[Women's space] gives them a voice...to learn that it (male violence) is not the women's problem in that they are not at fault. It empowers women. Usually women are dominated by men in the wider world, women take on a different viewpoint about what a woman is, if men are present, women feel disempowered given that they are victims of male violence."

The claim of providing a safe space for clients was also made by interviewees whose organisations provide a service to men. CASA4 for example, explained that the majority of male clients were adult men who had been sexually abused in childhood rather than men who had recently been traumatised. She was aware that the presence of men could cause anxiety for female clients who were recently assaulted and consciously avoided women and men sitting together in the waiting space.

CASA4: "I think because we are dealing with sexual assault some women might feel really uncomfortable to be sitting in close proximity to a man. We try to keep them separate when we can and we only try to have a couple of women in the waiting room at one time even though it is quite a small space..."

There was also an awareness of how easily women's space and the feeling of safety it provides can be compromised. WR2 too saw a problem with the presence of men at any level, including trades and other service men.

WR2: "If it is women-only it's a safe space and we don't have to engage in some of those power plays that we do if men are around...but I know whenever we've had like a male servicing the photocopier, or something like that, suddenly it just feels like there's some underlying tension in the place in terms of having clients here. Only because then we are not offering what we say we do, which is a woman only space, and somehow the dynamics just feel differently."

WR2 expressed concern about what she saw as a trend to include men in organisations that had previously been for women only.

WR2: "We want to hang on to a woman only space 'cos there are just so few spaces for them... as I've said we are becoming a bit more casual and there's now men's behaviour change programs. We wouldn't want it that they are all coming together, that men and women are coming together for counselling and stuff like that but yeah down the track things might change."

CASA7 was initially supportive of providing a service for both women and men as well as for transgender inclusion. Her attitude was that their feminist philosophy was "too heavy on the gender stuff" and that their focus should be on helping all people who needed support after sexual assault. She felt too that men needed to be included in events such as Reclaim the $N i g h t^{1}$ to gain their support for women's issues. When she visited a centre that had struggled with a transgender challenge and "thought through the issues" her attitude changed dramatically. She is now supportive of women-only space even though the service that she manages has both male and female clients and employs a male counsellor.

CASA7: "My opinion on women's only space...You know what! I've changed my thinking on that in the last six 
months. My thinking was, "we are all people, we all have the same rights, you should focus on the abuse or the service that's provided...I met [name of person at other Centre] and she spent three hours with me, talked my head off. In the end I left because I was so overwhelmed because I couldn't take another challenge. I asked her about that [being women only] and I said but men are sexually assaulted and men are victims and she said 'they can go somewhere else'. After talking to [name] and her staff and seeing that Centre, I thought 'Yeah you are right, so that was a real turning point for my consciousness awareness thinking, ahm and I've come back quite challenged by that ... and so I come back with all this YEAH to 'OK better deal with this'."

CASA7, through her meeting at the other Centre, became aware of the implications for women of allowing men into what was women-only space. From this meeting she also came to appreciate the unique experiences of women born and raised female, the implications of recognising MTFs as women, given that they had been born and raised male, and of allowing MTFs to become both workers and clients in their organisations.

Like CASA7 had initially done, many of the women interviewed for this study based their thinking about transgender inclusion within an anti-discrimination framework. They struggled with the idea of discriminating against people who claimed to be women, and hesitated to deny the womanhood of MTF transgenders. Nevertheless they generally felt strongly about providing a safe space for women clients and victims of physical and sexual abuse recognising the need for safety from perpetrators as described by Herman (1992). Because the perpetrators are generally men, a safe space usually meant the exclusion of men. The exclusion of MTF transgenders depended on whether or not the interviewees considered them to be women or men, as will be discussed in the next section which explores the policies that Centres had about the employment of men.

\section{Employment policies}

The focus of employment policies in those centres that had formal policies was on whether or not they should employ men. Some had non-discrimination policies and were open to employing men as well as women, though generally most employees were women. Five of the interviewees had formally applied for a legal exemption and were able to legally discriminate against men while others had an informal policy to exclude the employment of men but had not formalised that exclusion legally.

CASA7 was aware that the rights of one group that is male workers, to equal employment opportunity, could infringe on the rights or needs of another group, that is, female clients' need for a safe women-only space.

CASA7: "I still haven't got around to investigating how to get an exemption. I need to do it, (long silence) because I know we've got obligations as employers but our primary obligation is to our clients so that's where we would have to start from. How would the impression this person creates be reacted to by our clients."
Some interviewees commented on the fact that clients overwhelmingly preferred a female counsellor.

CASA1: "It is women workers by demand. Even male clients prefer a woman counsellor even though they can ask for a male. We have had three requests for a male counsellor in the past four years."

CASA4: "We don't have an exemption with the Equal Opportunity Commission so we don't um, our employment is based on experience and demand we actually don't have demand for a male counsellor advocate... Mmm...Yes I think two in my ten years, only two males in ten years have asked for a male counsellor. Whereas other CASAs they do employ male counsellors...yes."

The centre that CASA7 represented was the only one of the sample that employed a male counsellor at the time of the interviews. She said that her personal preference is to employ women however they did not have a legal exemption. CASA7 put restrictions on the male counsellor's activities, especially in the first contact phase when a client first contacts the centre either by phone or in person. The restrictions are placed on him because the client may be a woman who has recently been assaulted by a man. This rule is in the recognition that being faced with a male worker might be intimidating for a recently traumatised woman. It is at this first level of contact that questions about the suitability of MTF workers, who generally have masculine voices, and sometimes a masculine appearance is raised.

\section{Employment policies: MTF transgenders}

While some centres had applied for a legal exemption to allow them to employ women only, such exemptions were not sought to exclude MTF transgenders. The interviews revealed that many of the managers had limited awareness of transgenderism and the potential implications of transinclusion for their organisations, for their staff and clients and for the integrity of the services they offer. Most of the interviewees were not able to say with conviction whether or not they would employ an MTF.

CASA4, represented a centre that did not have a formal employment policy. Although they did not employ men, and took care to avoid men and women sitting together in the waiting room, they had not considered the employment of transgenders.

CASA4: "Ah an interesting question ah...it's not something that we've faced as an issue um (long pause) in terms of employment policy um yeah I'm not sure I can answer that um again I think the same policy can apply."

The 'policy' being non-employment of men based on demand, "we actually don't have demand for a male counsellor".

The response of WH3, who is a supporter of women-only space, was typical.

WH3: "No, no policy on either [employees or clients]...We have not decided whether that means born as a woman or identifies as a woman. I've been here in this position 
2 years and it's only been raised once and the agreement was...ahh virtually that issue we haven't come to an organisational position on it."

The opinions about trans-inclusion differed significantly and depended entirely on whether they believed MTFs to be real women and whether or not they placed importance on the different socialisation experiences of women born and raised female, of men born and raised male, and men born and raised male but identifying as women in adulthood.

Those centres that did have informal policies about MTF transgenders had inclusion policies. Four of the interviewees said that they would employ an MTF worker. According to those interviewees, the criteria for them, was merit, whether or not the applicant was the best person for the job. The likelihood that a masculine appearing MTF transgender might compromise feelings of safety for their female clients was not considered.

WH1 is a centre that does have a legal exemption to exclude the employment of men. They also have a strong policy of a safe woman only space which, as was seen earlier, was to provide a "cooperative female environment" that was "mainly safe from men". Nevertheless they were open to employing MTF workers.

WH1: "We are of the view here that we would employ the most suitable person that could very well be a transgender woman -we may not even know...if they were considered the best person for the job then that would be because of their skills and because of who they are and sure that would bridge any difficulties, and ahm, they would be supported here by management."

This was an intriguing response from an organisation that did not employ men because the merit argument could be equally put forward to justify the employment of men. Their decision, it transpired, was based on the opinion that an MTF was a woman. When asked if that would apply even if the applicant is obviously an MTF transgender the response was still affirmative.

WH1: "Even an obvious transgender woman if that person was the best person for the job then they would be offered the job. They would need to identify as a woman. We have a formal exemption of employing men but not transgendered women and it probably would not be legal to discriminate. I think that would be out and out discrimination."

The applicant's qualifications and skills were put forward as the primary concern of all interviewees who said that they would employ MTF transgenders.

CASA6: "Well I suppose ah we don't have a clear view or a policy to exclude male or trans workers, it's just what has evolved over time, who has applied and what seems to work. I would be looking at their experience and their qualifications and their commitment to um our philosophical stand...and I think [employing organisation] would be clear about the guidelines that we would have to follow. A trans-woman counsellor, I ahm I don't see that as a problem though I would say that I mean if a counsellor is a good counsellor that's...that's what works um and it's their connection with the client and that relationship that they have with the client...I would imagine it would be the same [with an MTF]. We have had in the past [male counsellors] other CASAs employ them as counsellors."

Yet earlier in the interview CASA6 had explained that their workers were all female and that both their female and male clients preferred to work with a woman.

CASA6: “The workers, they're all female. It's not written in our policy as such it's just seen as probably because of preference...the client that they prefer to work with a female counsellor and not male counsellors."

Interviewees like CASA6 and others had not considered that an MTF could have a masculine sounding voice or appearance which might cause clients to think that they were talking to a man, thus compromising the feeling of safety to which they believed their clients had a right. CASA7 recognised this as a problem. CASA7 whose policies placed restrictions on their male counsellor also felt uncomfortable about MTF transgenders, "We do not have policies on transgenders as workers but I realise that a trans-woman could trigger trauma...a male voice and figure can be intimidating for women who have been traumatised by a man". She recognised that an MTF transgender could have a masculine sounding voice. Nevertheless she was not able to say whether or not they would exclude MTF workers and was open to accepting MTF clients if they "looked like women".

A minority of interviewees (four) said they would prefer to exclude MTF transgenders, recognising the different socialisation that women and men experience.

CASA2: "We have a strong women only policy. We even try to get female 'tradies'. MTFs have different experiences and stories growing up in a culture that defines masculinity and femininity....We would not employ a transgender as a counsellor. But it has never been discussed or addressed or challenged."

WH3 was one of the interviewees who was adamant that they regard women's space essential for the safety of their clients and that even the presence of a male delivery person or a gardener could compromise a client's feeling of safety. They recognise that an MTF could also compromise this feeling of safety.

WH3: "Yes technically a transgender could gain the technical knowledge they would need to perform any of the jobs in the organisation but they wouldn't come from a lived experience and that plays a role in the services that we do offer medically and professionally as well. Again that they may look or sound like a man that therefore that would or could impact on [other] women's sense of safety when accessing the service if they think that they are accessing a service run by women."

Although WH3 said she would not employ an MTF her centre did not have a policy about transgender inclusion. 
Whilst expressing strong feelings about maintaining a safe women-only space she was mindful that she was expressing her own opinion and not that of her management.

WH3: "Even with administrative type work...still it's that philosophical issue of determining if they are born women or by identifying as women. My own personal feelings yeah probably I would go for exclusion. The organisation might come to a different position as to my own personal politics."

A final factor that influenced the interviewee's opinions about the employment of MTFs was whether or not they had previous experience with MTFs either as workers or as clients.

\section{Experience with MTF transgender workers}

Two of the centres represented by the interviewees had employed MTF workers. One of the interviewees was CASA5 who had spoken strongly in support of women-only space and whose personal belief was that an MTF was not a woman.

CASA5: "We have had an experience with a trannie. It is an issue in this organisation. The biggest thing is the lack of consensus about what is a woman, it always come back to that issue - how do we define woman. They think they feel like women but they have never been women so they would never know. I am a very strong supporter of women's space. Men who claim they are women inside have no idea of what it is to be a woman and someone else will say 'if she is a trans-woman then she is a woman'."

The experience that CASA5 had with an MTF worker had resulted in strong disagreement among the staff which the centre was attempting to resolve.

CASA5: "I would not employ a transgender but that's just one person's response because there is no policy. We have had lots of debate since our experience with transgenders and are developing a policy. We are also developing a philosophical framework. I have spoken to a few people and there is a lot of debate and the issue remains contentious."

One of the main issues that came out of these experiences was that although MTFs had the technical skills needed to do their job, they had little understanding about gender. They did not appreciate that the life experiences of heterosexual women, lesbians, bisexual women and transgenders were different and that these differences needed to be understood by workers in order to meet their respective needs. For example one of the past workers in one of the centres involved in this study was an MTF transgender. The interviewee, who had found this problematic, explained that this person ran workshops for women. "He ran a regular workshop for lesbian, bisexual and trans-women in the same workshop without any understanding that their life experiences are different." She felt that this worker's understanding of the gender power issues involved in treating female identified clients as a homogenous group seemed to be limited.

\section{MTFs as clients}

It was more common for the centres to have policies about whether or not to accept MTFs as clients but nevertheless reactions were mixed. The implications of accepting MTF clients differed depending on the type of service offered.

\section{Women's health centres}

The staff in Women's Health Centres are specially trained to understand and manage health concerns that are peculiar to women. They are not trained to deal with issues around sex realignment surgery nor MTF hormone treatment, nor are they trained in the special mental health issues experienced by MTFs which include the trauma of questioning gender identity, coming out as a transgender, transitioning to another sex and adjusting to life as the opposite sex. Furthermore inclusion of MTF clients in women's services such as women's health centres results in the neglect of women's issues spoken of by Kaplan (1996) and Freedman (1979). In this case it is a diversion of their primary focus on women's health in order to devote time to MTF issues such as hormone treatment and sex realignment surgery issues.

All of the women's health centres in this study admitted only clients who they considered to be female, but for some this included MTF transgenders. Those who accepted MTFs did so in the belief that a man who identifies as a woman, is a woman. For the same reason they excluded FTM transgenders in the belief that a woman who identifies as a man, is a man.

WH3 was one who rejected MTF transgenders as workers but was prepared to accept them as clients, although she acknowledged their complex health issues. She was adamant though that they would be accepted only if,

WH3: “...they sound like a woman...we don't require, we don't ask if they are trans-women or not. If they sounded like a man-even-we don't actually...I don't think we would even say 'are you a woman?' we actually haven't discussed it, we don't have a policy on that."

For WH2 the debate was more fundamental than defining a woman. They were open to MTFs as clients but acknowledged the complex health issues. They would have preferred not to include transgenders however they feared that if they acted in an exclusionary manner they would lose their funding.

The centre that WH1 represented had a trans-inclusion policy for both workers and clients because management believed MTFs to be women. They had some experience with trans-inclusion and had liaised formally with a transgender support group. WH1, as discussed previously, strongly supported women-only space and held a legal exemption to exclude male workers and to employ only women. She also stated that they admitted only women clients, however that included MTF transgenders. Her personal view was that MTFs were women like any other. "What we did I think it was around [year] we actually formed a policy about transgender clients and our policy is to recognise and provide services to transgender people". Their formal policy referred to the provision of "...services to MTFs who live and identify as a woman". They also accepted female to male transgenders but only whilst they were still transitioning and only if they still 
identified as a woman even though they presumably had women's health concerns.

WH1: "Also we would see transgender people who are transitioning from female to male. If the health issues relate to their female self then we would certainly take that very seriously, now if the health issues related to their male self and they were living as men, I think the word 'living' is very significant because the policy is that we recognise and provide services to transgender people who identify and live as women...If they have the privileges of a man, because they're appearing and living as a man...Yes they should go to mainstream health service."

When asked about the workers' training she confirmed that they have special training and expertise in women's health issues however not in male health issues such as prostate problems, nor in health issues related to sex change and monitoring of hormone treatment. The special training of their staff however was relevant for the health issues of FTMs except for those relating to sex change and monitoring of hormone treatment. MTFs would present with health issues that relate to hormone replacement therapy or medical issues arising out of genital reconstruction surgery or, because they have genetic male bodies, they would present with male health issues, none of which workers in women's health are generally trained to deal with.

WH1: "No anything to do with a male body...Yeah that would depend on the complexity of what was needed. Um I was going to say, oh yes that when we were forming the transgender policy um the medical staff here believe that they weren't, they didn't have expertise in hormone replacement therapy...or gender realignment surgery issues to help the client...they would probably refer for those issues."

The centre rejected FTMs but were prepared to accept MTFs for whose health needs they had no training or expertise. The question then arose as to whether the workers should be trained to deal with MTF issues. WH1 explained that they had been approached by a transgender support group who asked them to help MTFs monitor their hormone treatment. They were offered help with information about transgenderism as well as to develop a policy.

WH1: "I think at the time there were other women's health services, or women's services that were quite nervous about transgender issues. So it was quite timely and we had the board and staff come together and we spent the whole day talking through the issues..."

WH1 admitted that at the time the policy was formed there was "some robust discussion around feminism, violence against women and what it is to be a woman".

WH1: "Most people seemed to be coming from a similar view point...someone is identifying as a woman they are a woman. The discussion ended that if a person presents as a woman then they are. Yes in the end we got to that but there were some disagreements about that earlier on. Oh well the Simone de Beauvoir quote 'one is not born a woman one is made a woman'."

We then discussed the meaning of de Beauvoir's quote and that in fact the quote refers to social conditioning.

WH1: "Ahmm certainly, some people in the discussion were concerned about that. They felt that a man to have lived as a male is to have experienced privileges that none of us as women have ever experienced ahm but we did... there was an acknowledgement that we've generally accepted that people who are questioning their gender, and with that people who are transitioning to people who are transgender they experience enormous disadvantages and discrimination and which again we actually as women perhaps have never questioned, to question gender we could not imagine."

From the discussions $\mathrm{WH} 1$ gained the impression that most of the workers at the centre agreed that MTFs should be included. The perspective of WH1 was that "some people felt they needed to learn more but certainly a lot of cooperation and intent to be equitable". However an email interviewee who had worked at the centre at the time said that the conflict experienced by the workers, who had polarised, was severe. She had been present during discussions with MTF representatives and when she asked them why they did not go to a transgender support group to have their needs met, one of them, "held forth about wanting to be accepted as a woman and wanting to be among women...to see his identity confirmed by being among women".

\section{Refuges and CASAs}

Physical and sexual assault that may result in the victim needing safe refuge and counselling is something that is experienced by MTFs as well as by women born and raised female though in both cases it is predominantly men born and raised male who are the perpetrators. From the perspective of MTFs who believe themselves to be women, they, as victims of male violence, should also have the right to seek refuge in women's refuges and seek emotional support and counselling from CASAs. The interviewees in this study had mixed feelings.

WR2's response to this question exemplified the confusion some of the participants felt. When asked how she felt about transgenders as clients she replied quickly, "No we're very clear that it is only women and children we work with." But then thought further about her reply,

WR2: "Aahh I think if she identifies as a women ahh I think she'd meet the criteria. And similarly we are not out to, we don't make presumptions like if an aboriginal or Torres Islander women we don't make presumptions like 'you don't look like.... And given our political view ahm that through patriarchy men they are socialised as men even if they have been but they don't associate themselves as male I think that's what I find a bit difficult. So they have that socialisation, privileges of masculinity, they still feel like male, yeah but they've rejected that I suppose that they are working actively toward the 
empowerment of women but then again you can't presume that either, like you can't presume that every woman's a feminist, or presume that every feminist is a lesbian or every lesbian a feminist. But that's interesting 'cos when faced with the reality I'm not really sure it would be that straightforward..."

CASA4 also took the view that if MTFs consider themselves to be women, then they are women.

CASA4: "Yes certainly I think over the last three or four years we have seen three transgender women ahm it's not an issue for us we very much come from a feminist understanding, of a philosophy that informs our service but we would apply that to mean that it depends on how the person is identifying and if they're identifying as a woman then that's how we would support them."

CASA5 had demonstrated a deep understanding of the need for women-only space, recognising the power dynamics in male/female relationships and importantly how women restrict their behaviour and points of discussion when men were present. Nevertheless she felt unsure of how to respond on the issue of MTF clients. On the one hand she recognised that MTFs have needs and rights, but on the other hand she also recognised the substantial differences between women born and raised female and MTF transgenders.

CASA5: "They come with a different set of experiences when they grow up, and stories, and not to minimise their growing up in a culture that defines gender narrowly and rigidly, restricts free expression. The male and female experience of socialisation is different...I feel conflicted and confused about where I stand. It brings up contradictory things for me, very complicated."

In the end she re-affirmed the need for retaining womenonly spaces suggesting that MTFs were not women.

CASA5: "One of the main things is that this is a women's service but I see there needs to be services there for transgenders perhaps separate services, some that are also for trans-women and some that are just for women."

One of the services offered by CASAs and women's refuges was group discussion therapy facilitated by a skilled counsellor. It was here that concerns about MTFs mixing with clients who were women raised female was greatest. CASA5 who personally favoured separate services for MTFs gave this as an example of the difficulties of treating MTFs as women.

CASA5: "Say in a support group, there is not an official response so my own opinion, even though the person may be on side maybe if other women knew it would be challenging for the women - so it would take away the safe space for some."

CASA4 who accepted MTFs as women and therefore as clients, nevertheless recognised that the different historical social and political backgrounds of MTFs and women raised female would make it inappropriate to have such women and MTFs in the same group.

CASA4: "When I spoke to my colleagues one of the things potentially in terms of impact on service users that we considered that we hadn't really looked at were around groups, e.g. support groups and group sessions, and again currently we don't offer many groups for men because we haven't had the demand. Yep they're structurally facilitated groups, we run around three or four each year for survivors of child sexual assault as a group. It's run for adults and one of the things that came up was gee how would we handle that if a transgender woman was saying 'I want to access a support group'. Currently we have separate groups for males and females. That was a really interesting issue that we again we've not been faced with that dilemma um but we may and how would we handle that...and how would we try and balance everyone's needs and rights 'cos the rights based perspective but how would we begin to manage that."

CASA6 had experience of attempts to run mixed groups and felt that her clients would object to the presence of MTFs, nevertheless she was prepared to run groups with MTFs present.

CASA6: "But what I am aware of is say at times when we've gone to run a group um that the women in the group are very clear about not wanting any male survivors in that group. They just want it to be all female and it, whether the male is a victim/survivor is totally irrelevant to them they just see very black and white and 'no they're males'...But I would if I was in the position where there were, clients that were transgender that wanted to be in a group I know that there would be a group of women that wouldn't want that so they would have their own group time and there would be a group of women that it [the presence of MTFs] wouldn't bother so...include them in another group...so that way they would have their women only space at a different time."

WR1 has had experiences with MTF clients. WR1 has a non-discrimination policy. Its clients are referred from mainstream health and police and so the workers feel they have no choice but to accept whoever is referred to them. WR1 had a person referred to them who was referred as a woman and presented in women's clothing. They realised through mannerisms and an Adams apple that he was either an MTF or a transvestite. However, because he had been referred and because of anti-discrimination laws, they felt they had no choice but to accept him as a client.

They originally placed him in one of the accommodation units with women, but the women complained and said they "did not want someone with a penis with them". One said, "I'm not going in there, he's got a penis." They could not place him with women and children and so placed him on his own for 6 weeks, which had the effect of denying space to other women. The workers did not see this as discrimination against women seeking refuge and unable to be placed, rather they saw it as a duty of care to the female clients and their children. The workers at the refuge found the situation 
stressful as they did not know how to deal with it and were afraid of breaking the law by discriminating.

\section{Discussion}

A safe environment for women to have their emotional and physical health needs met or to find refuge from male violence was a commitment espoused by all of the participants. Women escaping from assault could find refuge and obtain counselling from professionals in an environment where they did not have to face men. The participants also acknowledged the opportunities for women to share experiences with other women who may have had similar experiences. In women's health centres too, such support was available and women were able to discuss sensitive health issues with specially trained female health professionals. This opportunity of having a voice, for consciousness raising and gaining mutual understanding was reported by participants to be empowering and valued by women. Participants agreed that the presence of men inhibits women from opening up for two main reasons. Firstly it is violence from men that they are escaping, or it is uniquely female issues for which they are seeking health care. Secondly and importantly men have different life experiences and women's perception is that they are not able to empathise in the same way that another woman who has had similar life experiences can.

The strong support for a women-only space was exemplified in the centres' formal and informal employment policies. Only one of the centres employed a male counsellor and found this problematic. Most other centres either legally excluded men or simply did not employ men. Some had nondiscrimination policies however their employees were women.

Whilst there was general agreement about the employment of men, the employment of MTFs exposed confusion and contradiction. Opinions varied depending on whether they believed MTFs to be women or men. None of the centres held exemptions for MTFs and while most, but not all, felt uncomfortable about employing especially obvious MTFs, they were also mindful of not wanting to discriminate against another minority group.

Those centres that had informal policies about MTFs had inclusion policies. A minority of interviewees said that they would employ MTFs including some who had said that they would not employ men. Some of the interviewees who had spoken eloquently about the need for women-only space did not consider it a cause for concern that a masculine appearing MTF, or an MTF with a masculine voice, might compromise feelings of safety for female clients. Their lack of concern was based on their sincere belief that MTFs are women.

Men and MTFs have argued in various contexts that they are qualified and should have the right to work in women's services. However the one centre that employed a male counsellor and the two centres that had experience with MTF workers had found it problematic. For the interviewees the experience had exposed and confirmed their beliefs that men and MTFs did not understand gendered female and male socialisation and gender power and concluded that they were not able to empathise with the experiences of women. Such examples raise the question of whether the right of an MTF, or a man, to be a crisis counsellor is greater than the right of women, who are victims of male violence, to have safe refuge in women-only space.

MTF Nixon's defence (VRRWS, 2006) in Canada had been that "all persons must be assessed individually in relation to the services or employment being offered." However a win based on a merit selection policy would mean that men were potentially qualified for any position in any women's group; the Pandora's box referred to by Mathen (2004). If the merit argument is accepted in relation to employment in women's services it would open the door to MTFs and men and negate the reasons for which the services were set up in the first place.

Opinions about whether to accept MTFs as clients were also mixed, but interviewees generally were more open to MTF clients than to MTF workers, although once again their decisions depended on whether or not they believed MTFs to be women. This is interesting because some interviewees who wanted to accept MTFs as clients because they believed them to be women nevertheless wanted to reject them as workers. The issue of MTF clients revealed uncertainty and confusion as the interviewees struggled with the potential implications. Responsibility to clients who were women born and raised female was foremost. In the case of CASAs and women's health centres the only times that MTFs presence might compromise women's feelings of safety or inhibit women's involvement was felt to be in support groups or in 'public' space such as waiting rooms. Their consultations with counsellors or health professionals would be in private. In the case of women's refuges the potential to compromise women was greater as the refuge accommodation is shared accommodation. As was seen in the case of WR1 this was problematic for the women, if not for the MTF, when an MTF was housed with women in a women's refuge. The women residents protested about sharing accommodation with someone they immediately recognised as a man.

\section{Conclusion}

This article does not seek to prove that MTFs are women, or that they are not women. That is the crux of the 'Great Trans Debate' and the subject of another study. This article does however argue that the life experiences of women born and raised female and the experiences of MTFs, born and raised male, differ significantly and that male dominance and female submission is institutionalised in the socialisation experience. MTFs have had male socialisation, whether or not they felt comfortable in their assigned gender roles.

This article acknowledges that MTFs have special needs and equal rights before the law. However in the case of women-only space and in the current social and legal context, protecting the rights of one minority group, transgendered people, infringes on the rights of another minority group, women, with serious consequences for all women. The dilemma of managing the 'rights' perspective is the reason why many of the participants in this study opted for transgender inclusion, even while understanding the difficulties this posed for their female clients. Many other participants were prepared to take a stand and make the difficult decision that MTFs need to create their own safe space.

MTF inclusion in women-only spaces, whether as clients or as workers, compromises the rights of women to seek 
support in a context where they are with, and receive professional help from, people with whom they have shared experiences. The inclusion of men or MTFs results in the elimination of women-only space and re-assimilation into male dominated institutions. Such mainstreaming can potentially remove the focus from women's issues and return to a situation described by Kaplan (1996) where women's needs in health and refuge become invisible and neglected.

As proposed by Freedman (1979) the decline of the gains achieved for women by feminism is under threat by the erasure of women-only space. Freedman argues that the building of coalitions of women's groups and continuation of separatism is crucial. In this paper I argue in support of Freedman (1979). Trans-inclusion then is one of the greatest threats faced by women.

\section{Endnote}

${ }^{1}$ Reclaim the night. This is a women's annual march to protest against men's sexual violence. See: http://www.isis.aust.com/rtn/.

\section{References}

Blair, Karen J. (1984). The limits of sisterhood: The woman's building in Seattle, 1908 1921. Frontiers: A Journal of Women's Studies, 8(1), 4552.

Burns, Christine (2005). Trans rights campaigner and educator. Web Site, http:/ / www.pfc.org.uk/ files/CBurnsOct2005.pdf

Collis, Jill, \& Hussy, Roger (2003). Business research: A guide for undergraduate and postgraduate students. London: MacMillan.

Cowell, Roberta (1954). Roberta Cowell's story: An autobiography. London: Heinemann.

Crotty, Michael (1998). The foundations of social research: Meaning and perspective in the research process: Meaning and perspective in the research process. Crows Nest, NSW: Allen \& Unwin.

Darke, Julie, \& Cope, Allison (2002). Julie Darke and Allison Cope for the Women/ Trans Dialogue Planning Commitee and the Trans Allience Society, Trans Inclusion Policy Manual for Women's Organizations Winter 2002. http:// www.transalliancesociety.org/education/documents/02womenpolicy/ pdf

Devor, Aaron (2004). Witnessing and mirroring: A fourteen stage model of transsexual identity formation. Journal of Gay and Lesbian Psychotherapy, $8(1 / 2), 4167$.

Eminism.org (2006). The great trans debate of summer 2005. http://eminism. org/interchange/2005/20050803 wmstl.html (retrieved 16/08/2006).

Feinberg, Leslie (1996). Transgender warriors: Making history from Joan Arc to Rupaul. Boston: Beacon Press.

Freedman, Estelle (1979). Separatism as a strategy: Female institution building and American feminism, 1870 1930. Feminist Studies, 5(3), 512519.

Greer, Germaine (1999). The whole woman. Milson's Point, NSW: Doubleday.

Gurney, Karen (2006). Bad policy, bad law: The derogation of human rights for people with transsexualism since the 'justice' statement. Alternative Law Journal Articles, 31, 3638

Hausman, Ken (2003). Clinical and research news: Controversy continues to grow over DSM's GID diagnosis. Psychiatric News, 38(14), 2526.

Herman, Judith Lewis (1992). Trauma and recovery: The aftermath of violence From domestic abuse to political terror. New York: Harper Collins.

Jeffreys, Sheila (1997). Transgender activism: A lesbian feminist perspective. Journal of Lesbian Studies, 1(3/4), 5574.

Jeffreys, Sheila (2008). They know it when they see it: The UK gender recognition act 2004. Journal of Politics and International Relations, 10(2), 328345.
Johnson, Vivien (1981). The last resort: A women's refuge. Ringwood: Penguin Books.

Kaplan, Gisela (1996). The meagre harvest: The Australian women's movement 1950s 1990s. St Leonards, NSW: Allen and Unwin.

Kline, Jodie (unpublished). Discovering lesbian community? An exploration of lesbians' experiences and perceptions of shared community. Department of Political Science, The University of Melbourne, (unpublished PhD).

Lake, Marilyn (1999). Getting equal: The history of Australian feminism. St Leonards, NSW: Allen and Unwin.

Lyon Martin Health Services (2008). Our mission. http://www.lyon martin. org

McDonald, Myfanwy (2006). An other space: Between and beyond lesbian normativity and trans normativity. Journal of Lesbian Studies, 10(1/2), 201214.

Mantilla, Karla (2000). Men in ewes' clothing: The stealth politics of the transgender movement. Off Our Backs, 512 April.

Mathen, Carissima (2004). Transgendered persons and feminist strategy. Canadian Journal of Women and the Law, 16(2), 291316.

May, Lois (2005). Transgenders and intersexuals: Everything you over wanted to know but couldn't think of the question. Bowden, SA: East Street Publications.

Mayeda, Graham (2005). Re imaging feminist theory: Transgender identity, feminism and the law. CJWL/RFD, 423472.

Meyer, Jon (1982). The theory of gender identity disorders. Journal of the American Psychoanalytic Association, 30, 381418.

Morris, Belinda J. (2005). Commentary valuing women only spaces. Feminist Studies, 31(3), 619630.

Morris, Jan (1975). Conundrum. London: Coronet Books.

Murray, Suellen (2002). More than refuge: Changing responses to domestic violence. Crawley: University of Western Australia Press.

NHS Direct, Health encyclopaedia: Gender dysphoria, www.nhsdirect.nhs. uk/articles/article.aspx?ArticleID 435 retrieved June 2008.

Pearlman, Sarah (2006). Terms of connection: Mother talk about female to male transgender children. Journal of GLBT Family Studies, 2(3 4), 93122.

Pitts, Marian, Smith, Anthony, Mitchell, Anne, \& Patel, Sunil (2006). Private lives: A report on the health and wellbeing of GLBTI Australians, gay and lesbian health Victoria. The Australian Research Centre in Sex, Health and Society, La Trobe University

Price, Sarah (2007). Transsexual fights for her lesbian rights. Australian Woman Network, www.w o m a n.net/home/node/920

Raymond, Janice (1994). The transsexual empire: The making of the she male. New York: Teachers College Press Columbia University.

Rees, Mark (1996). Dear sir or madam: The autobiography of a female to male transsexual. London: Cassell.

Riger, Stephanie (1994). Challenges of success: Stages of growth in feminist organizations. Feminist Studies, 20(2), 275300.

Rottnek, Matthew (Ed.). (1999). Sissies and tomboys: Gender non conformity and homosexual childhood New York: New York University Press.

Ruby, Jennie (2003). Women only and feminist spaces. Off Our Backs, 1315 May June.

Stuart, Jaimie (2006). In another bracket: Trans acceptance in lesbian utopia. Journal of Lesbian Studies, 10(1/2), 215229.

Sweeney, Belinda (2004). Trans ending women's rights: The politics of trans inclusion in the age of gender. Women's Studies International Forum, 27(1), 7588.

The Gender Centre Inc. (2005). Kits and factsheets. www.gendercentre.org.au, Retrieved Wednesday 1st October, 2008.

The Gender Centre Inc. (2006). www.gendercentre.org.au/index1.html

VRRWS (2006). For women only. Produced by the Collective of Vancouver Rape Relief and Women's Shelter.

Wales, Melody (1999). The finest lesbian feminist artist. Xtra West, 163, 2122.

Webb, Christine (Ed.). (1986). Feminist practice in women's health Brisbane: John Wiley \& Sons. 